\title{
NUMERICAL INVESTIGATION OF THE PLUNGE STAGE IN FRICTION STIR WELDING USING VARIOUS TOOL PIN PROFILES
}

\begin{tabular}{|c|c|}
\hline Prashant Prakash $^{1}$ Shree Prakash Lal & Sanjay Kumar Jha2 $^{1}$ \\
Department of Production Engineering & Department of Production Engineering \\
Bilra Institute of Technology, Patna Campus & Bilra Institute of Technology, Mesra, Ranchi Ranchi, \\
Patna, Bihar, Pin Code 800014, India & Jharkhand, Pin Code 835215, India \\
prashant.prakash86@yahoo.co.in & sanjujha@ @otmail.com \\
\hline
\end{tabular}

\begin{abstract}
Friction stir welding (FSW) is a solid state joining process which uses a rotating tool consisting of a shoulder and a pin/probe. The shoulder applies a downward pressure to the work piece surface, generates heat through the friction and leads to plasticization of materials in the vicinity of pin. During traverse the rotating tool mixes the adjacent material in the stir zone, creating a joint without fusion. A better understanding of the plunge phase is critical with the growing role of friction stir welding and also in understanding tool wear in friction stir welding (FSW) of high strength alloys. This paper investigates the plunge stage in friction stir welding using various tool pin profiles through numerical modeling. A 3D finite element-based model (FEM) of the plunge stage was developed using the commercial code ABAQUS to study the thermo mechanical processes involved during the plunge stage. The strain rate and temperature-dependent Johnson-Cook material law is adopted in the FEM.
\end{abstract}

Keywords-Friction stir welding (FSW), ABAQUS, JohnsonCook law, Tool geometry, Temperature generation,

\section{INTRODUCTION}

In the last two decades, friction stir welding (FSW) has become a mature joining technology for aerospace, shipbuilding and automobile industries [1]. FSW has been successfully applied to weld similar and dissimilar metal as well as metal matrix composites alloys [2]. The FSW process have several advantages over fusion welding such as better retention of baseline material properties, fewer weld defects, low residual stresses and better dimensional stability of the welded structure [3]. With above all, FSW is also an environmentally cleaner process because this process does not produce smoke, fumes, arc glare. Further, profiled edge preparation or consumable filler material is not necessary so it is known as eco-friendly welding process [4].

The welding mechanism is based on the frictional heat generation process through the interaction of a nonconsumable tool having specially designed shoulder profile and pin profile that rotate and plunge to adjoining edges of the plates to be joined until the shoulder touches the surface of the material being welded and traversed along the weld line $[5,6]$. The direction of the tool rotation is opposite as the welding direction in one side half plate that is called the retreating side, while the tool rotation is same as the welding direction other side of half plate is called advancing side as given in Fig. 1. Frictional heat is generated through the interaction of hard material welding tool and material of the plate which is softening the plate material without reaching the melting point.

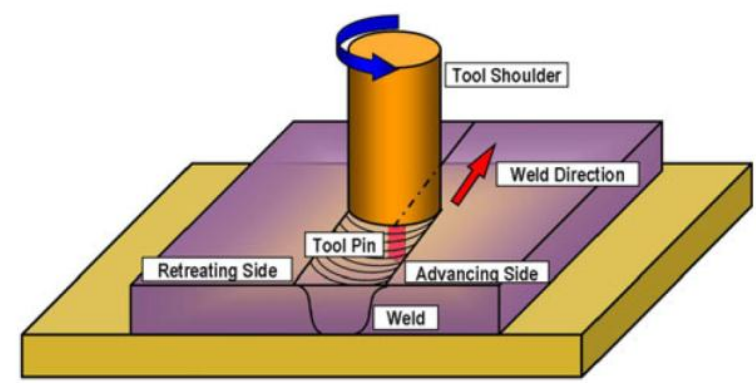

Fig. 1. Schematic of the friction stir welding (FSW) process [7].

In friction stir welding process, rotating tool plunge into the work piece material until the shoulder touches the surface of the material. Rotation of the tool produce significant amount of primary and secondary heat source. The frictional heat is generated from the contact between work piece and tool shoulder which is primary heat source. Deformation heat is generated from the contact between work piece and tool pin that is known as secondary heat source. The sound weld joint is produced by appropriate amount of heat generation and material flow in the process otherwise the weld joints develop with defects such as lack of fusion, lack of penetration, voids, tunnels, surface grooves, surface galling, excessive flash and nugget collapse [3].

The plunge stage is extremely important in friction stir welding (FSW) process because most of the primary thermo mechanical phenomenon is generated and the material undergoes large deformation due to the high temperatures and stresses involved in the process. Experimentally it is difficult to understand process physics of plunging phase due to highly dynamic nature of this phase. Numerical modeling provides valuable insight into the dynamic nature of FSW using finite element method (FEM). The FSW process has been investigated numerically using finite element method (FEM) by several researchers. S. Mandal [8] experimental and numerical investigates the plunge stage in friction stir welding in AA2024-T3 alloy. Frictional heat produce during plunge stage in friction stir welding [9]. Tool pin profiles effect can be modeled by FEM modeling in friction stir welding which show the temperature and stress distribution during welding process [10, 11]. Shoulder size significantly affects the temperature rise and the material deformation in friction stir welding but tool sizes and pin shapes also affect the temperature and stress distribution during friction stir welding $[12,13]$. Limited works have been reported by many people in numerical investigation of temperature and stress distribution in plunging stage. Hence further investigation is required for better understanding of plunging stage. This paper investigates 


\section{Asia Pacific Journals}

the plunge stage in friction stir welding using four different tool pin profiles using numerical modeling technique. A 3D finite element-based model (FEM) of the plunge stage have been developed using the commercial code ABAQUS to study the thermo mechanical processes. The strain rate and temperature-dependent Johnson-Cook material law is adopted in this analysis. Comparative studied have been explained temperature, weld nugget, stress and equivalent plastic strain profile during the plunging stage in friction stir welding.

\section{MODEL DESCRIPTION}

FE model is developed in the commercial code ABAQUS/Explicit using the Johnson-Cook material law, and Coulomb's Law of friction. Here the work piece of $40 \mathrm{X} 40 \mathrm{~mm}$ area and thickness of $3 \mathrm{~mm}$ is considered. The model consists of a deformable work piece and a rigid stir welding tool. The work piece is meshed using eight node coupled temperature displacement, brick elements (C3D8RT). The Johnson-Cook Johnson and Cook [14] equation (1) describes the flow stress as a product of the equivalent strain rate, temperature dependent terms and several parameters to adequate the real behavior of the materials.

$$
\sigma_{y}=\left[A+B\left(\varepsilon_{p}\right)^{n}\right]\left[1+C\left(\frac{\varepsilon_{p}}{\varepsilon_{o}}\right)\right]\left[1-\left(\frac{T-T_{\text {room }}}{T_{\text {mett }}-T_{\text {room }}}\right)^{m}\right]
$$

where Tmelt is the melting point or solidus temperature, Troom the ambient temperature, $T$ the effective temperature, $A$ the yield stress, $B$ the strain factor, $\mathrm{n}$ the strain exponent, $\mathrm{m}$ the temperature exponent, $\varepsilon p / \varepsilon 0$ the plastic strain and $C$ the strain rate factor. $A, B, C, n$, and $m$ are material/test constants for the Johnson-Cook strain rate dependent yield stress. The material properties of AA6061-T6, considered for simulations [15].

\section{A. Tool geometry}

The various tool pin geometry for simulation are shown in Fig. 2. The shoulder diameter, pin length and upper diameter of the pin are $16 \mathrm{~mm}, 3.3 \mathrm{~mm}$ and $6 \mathrm{~mm}$ respectively.
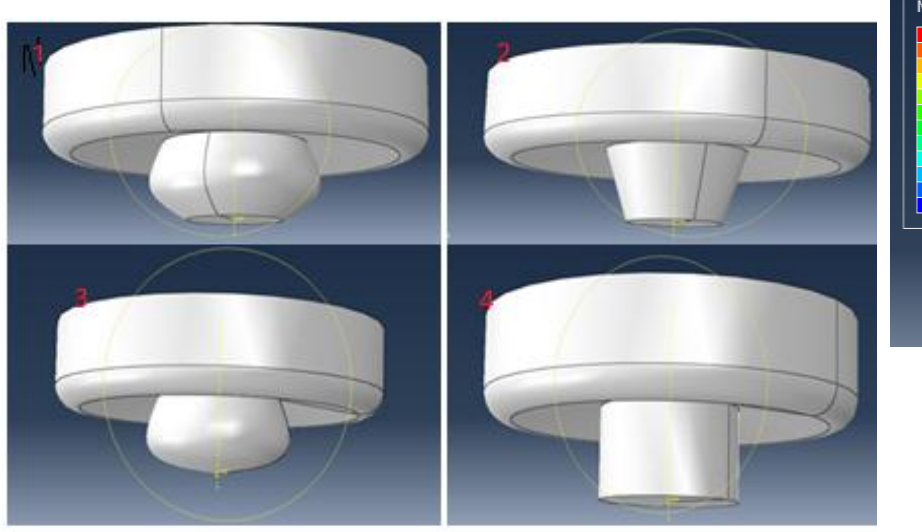

\section{B. Boundary condition}

The process parameters considered in present study are as follows: tool rotational speed of $300 \mathrm{rpm}$, plunge depth is 2.5 $\mathrm{mm}$, constant pressure $90 \mathrm{Mpa}$ apply on the tool shoulder surface and tool tilt angle of zero degree. The boundary conditions (work piece fixed) are shown in the fig.3.

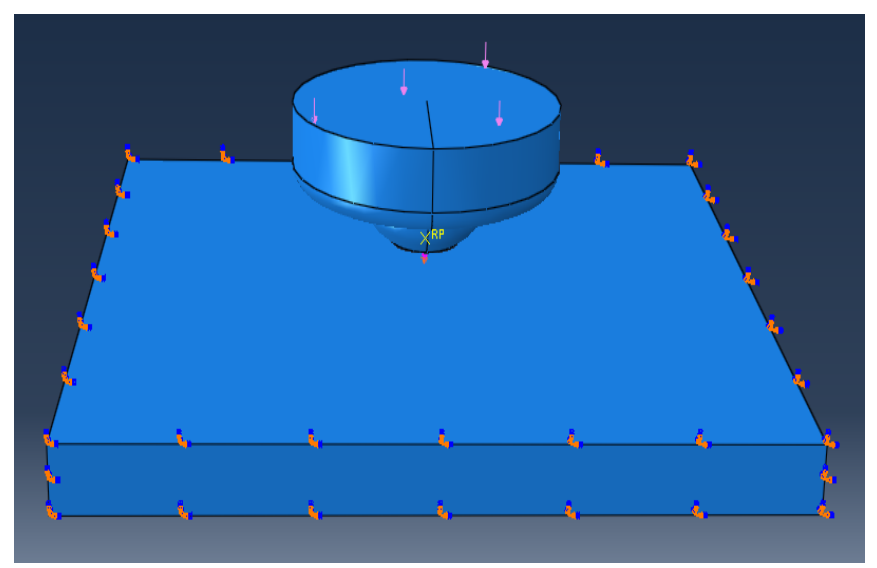

fig.3. Boundary condition apply on the model.

\section{RESULTS AND DisCUSSION}

Simulation has been conducted using four different tool pin profile to predict the temperature, weld nugget, stress and equivalent plastic strain profile during the plunging stage in friction stir welding. Comparative studies of different profile explain in the following sub sections:

\section{A. Comparison for Temperature Profile}

The temperature generations profile in the plunging state of four pin profiles are shown in figure 4, 5, 6 and 7. When the $1^{\text {st }}$ tool pin profile is used the maximum temperature is obtained $268{ }^{\circ} \mathrm{C}$. Similarly using the $2^{\text {nd }}, 3^{\text {rd }}$ and $4^{\text {th }}$ tool pin profile the maximum temperature generation during the plunging stage are $283^{\circ} \mathrm{C}, 276^{\circ} \mathrm{C}$ and $508^{\circ} \mathrm{C}$ respectively. It can be observed that maximum temperature is obtained by pin profile 4 which is useful for maximum heat generation during friction stir welding.

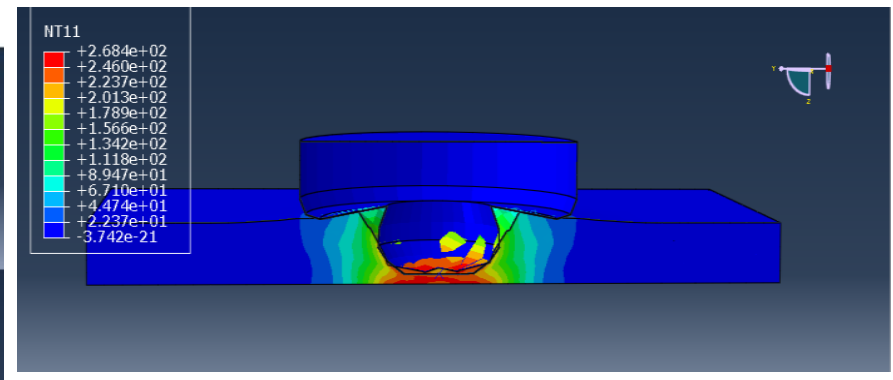

Fig.4. Temperature generation in workpiece with tool 1.

Fig. 2. Geometry of different tool pin employed. 


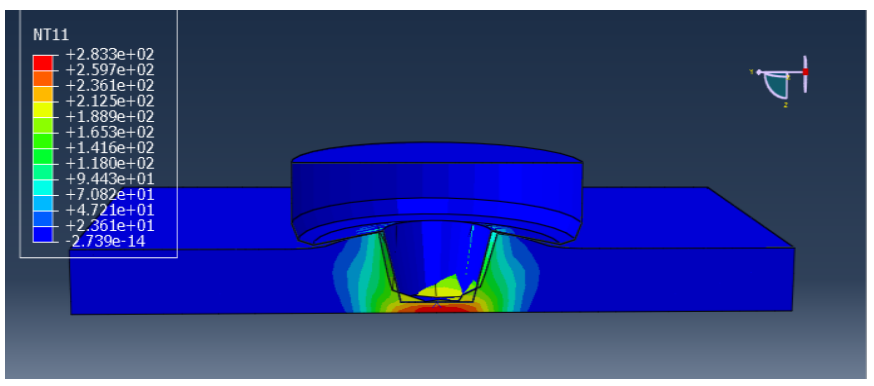

Fig.5. Temperature generation in workpiece with tool 2.

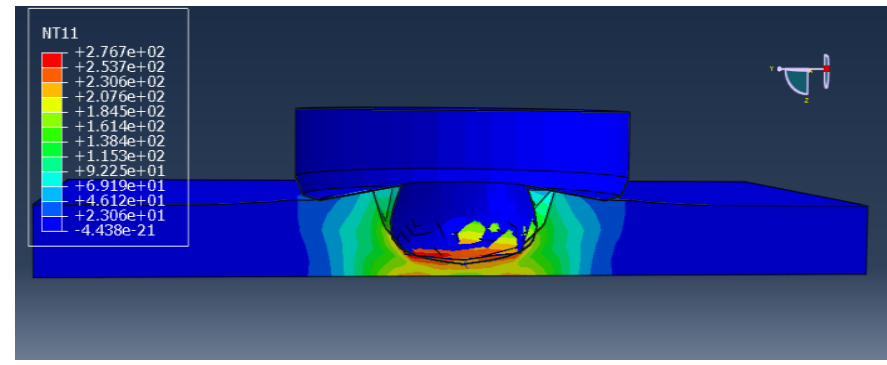

Fig.6. Temperature generation in workpiece with tool 3.

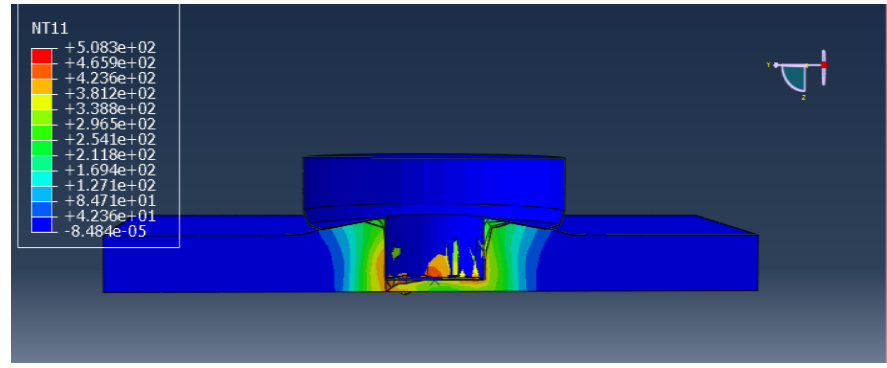

Fig.7. Temperature generation in workpiece with tool 4 .

\section{B. Comparison For Weld Nugget Profile}

The weld nugget profile in the plunging state of four pin profiles are shown in figure $8,9,10$ and 11 . It can be observed that the bigger weld nugget profile generated by using the $1^{\text {st }}$ and $3^{\text {rd }}$ as compare to $2^{\text {nd }}$ and $4^{\text {th }}$ tool pin profile.

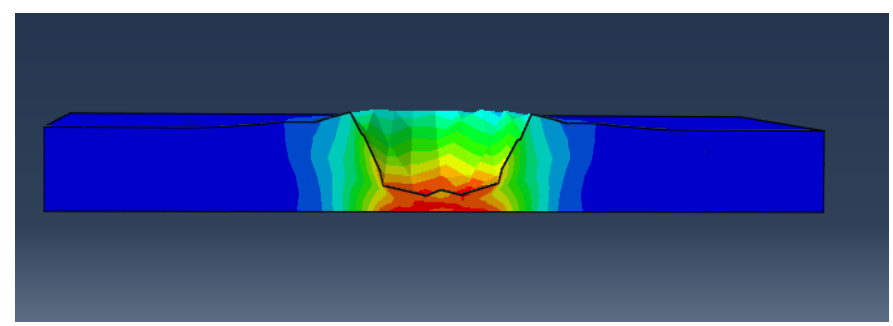

Fig.8. Weld Nugget Profile with tool 1.

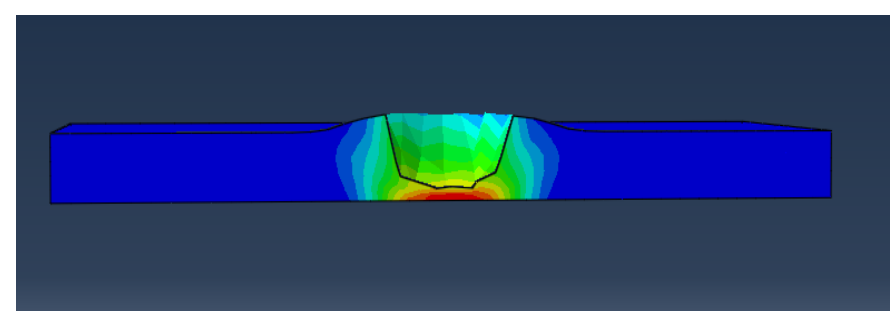

Fig.9. Weld Nugget Profile with tool 2.

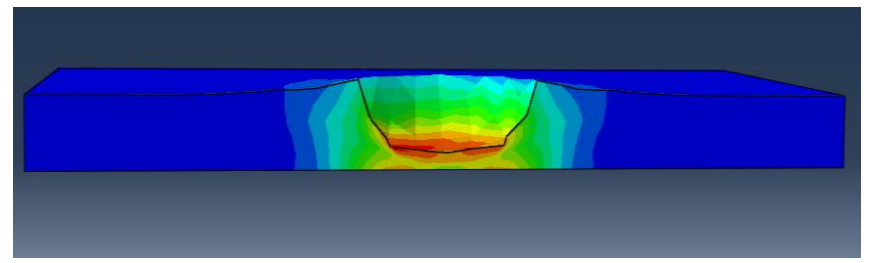

Fig.10. Weld Nugget Profile with tool 3.

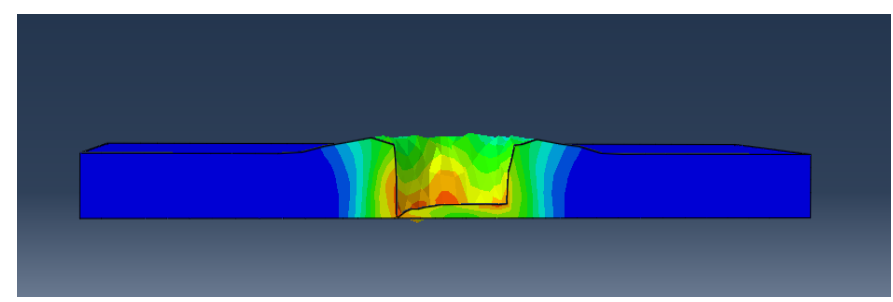

Fig.11. Weld Nugget Profile with tool 4.

\section{Comparison for Stress Profile}

The stress profile in the plunging state of four pin profiles are shown in figure 12,13,14 and 15. Maximum stress of pin profile 1 to 4 is around $390 \mathrm{Mpa}$. It can be observed that there is no significant variation in the maximum stress but stress distribution range in the work piece is larger in pin profile 3.

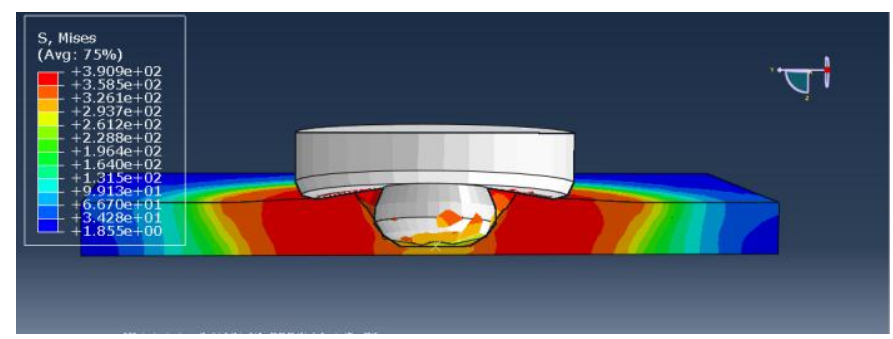

Fig.12. Stress Profile in workpiece with tool 1.

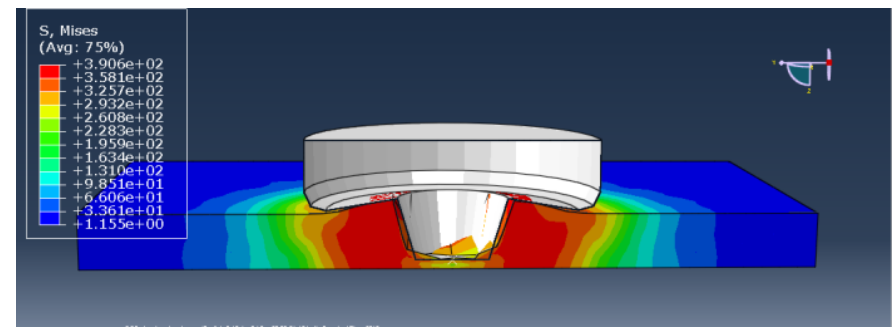

Fig.13. Stress Profile in workpiece with tool 2. 


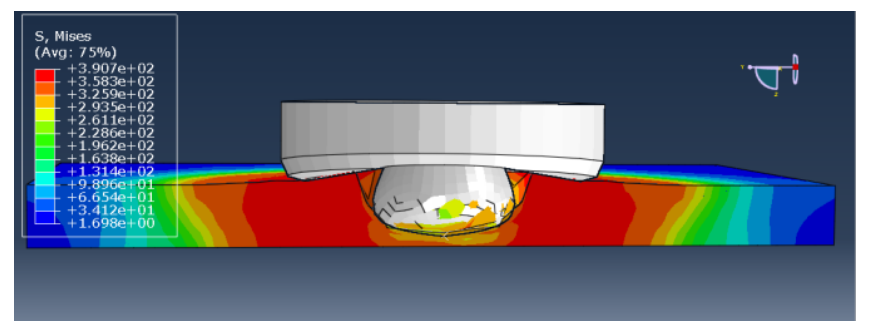

Fig.14. Stress Profile in workpiece with tool 3.

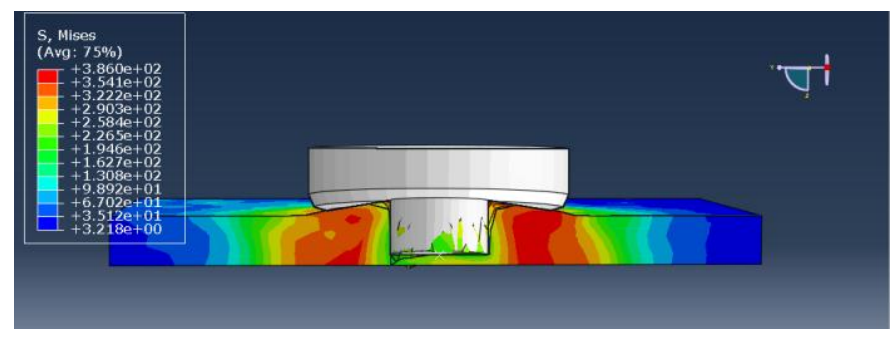

Fig.15. Stress Profile in workpiece with tool 4.

\section{Comparison for equivalent plastic strain profile}

The equivalent plastic strain profile in the plunging state of four pin profiles are shown in figure 16, 17, 18 and 19. Maximum equivalent plastic strain observed in pin profile 1 and minimum in 4.

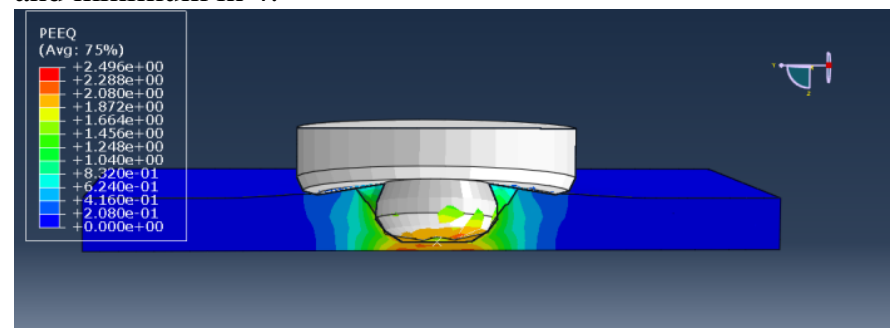

Fig.16. Equivalent plastic strain profile in workpiece with tool 1.

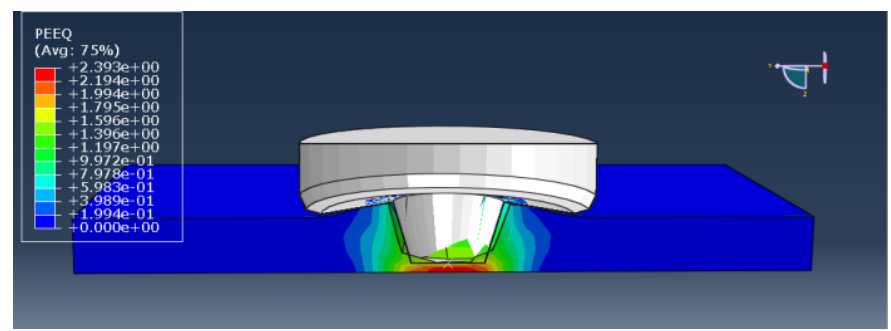

Fig.17. Equivalent plastic strain profile in workpiece with tool 2.

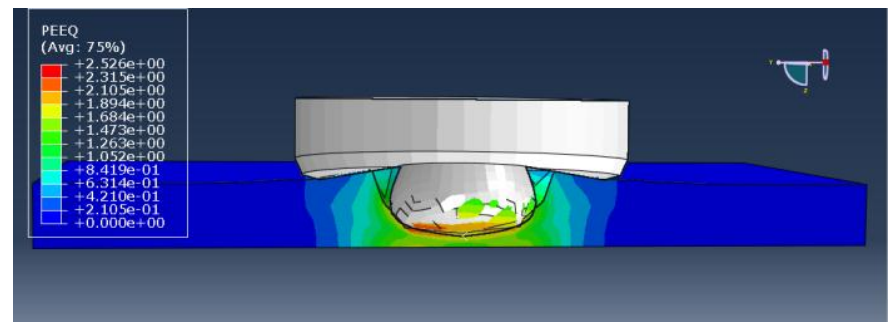

Fig.18. Equivalent plastic strain profile in workpiece with tool 3.

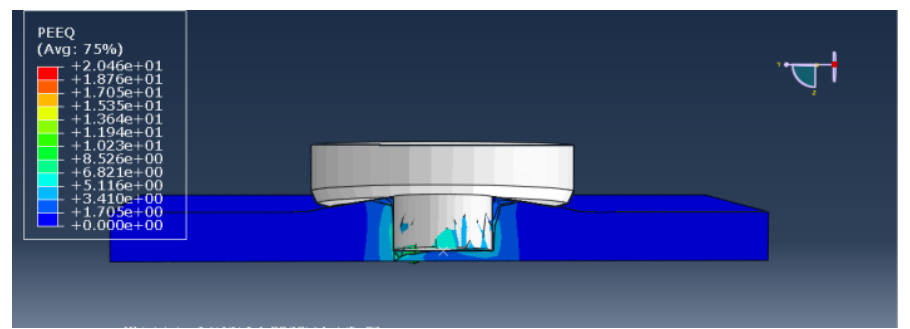

Fig.19. Equivalent plastic strain profile in workpiece with tool 4 .

\section{CONCLUSION}

Based on the numerical simulation the following conclusions are:

1. It can be observed that maximum temperature is obtained by pin profile 4 which is useful for maximum heat generation during friction stir welding.

2. It can be observed that the bigger weld nugget profile generated by using the $1^{\text {st }}$ and $3^{\text {rd }}$ as compare to $2^{\text {nd }}$ and $4^{\text {th }}$ tool pin profile.

3. It can be observed that the bigger weld nugget profile generated by using the $1^{\text {st }}$ and $3^{\text {rd }}$ as compare to $2^{\text {nd }}$ and $4^{\text {th }}$ tool pin profile.

4. Maximum equivalent plastic strain observed in pin profile 1 and minimum in 4.

\section{Acknowledgment}

The authors wish to acknowledge Birla Institute of Technology, Mesra, Ranchi for providing opportunity to pursue the research work in the area of Friction stir welding.

\section{References}

[1] N. T. Kumbhar, and K. Bhanumurthy, "Friction stir welding of Al 6061 alloy." Asian J. Exp. Sci 22.2, 2008, 63-74.

[2] G. Cam, "Friction stir welded structural materials: beyond Al-alloys," International Materials Reviews 56.1, 2011, 1-48.

[3] B.T. Gibson, D.H. Lammlein, T.J. Prater, W.R. Longhurst, C.D. Cox, M.C. Ballun,K.J. Dharmaraj, G.E. Cook, A.M. Strauss,"Friction stir welding: process, automation, and control," Journal of Manufacturing Processes 16.1,2014, 56-73.

[4] W. M. Thomas, K. I. Johnson, and C. S. Wiesner, "Friction stir weldingrecent developments in tool and process technologies," Advanced Engineering Materials 5.7 ,2003, 485-490.

[5] R. S. Mishra, and Z. Y. Ma, "Friction stir welding and processing." Materials Science and Engineering: R: Reports 50.1, 2005, 1-78. 


\section{Asia Pacific Journals}

[6] K. Kumar, , and S. V. Kailas. "The role of friction stir welding tool on material flow and weld formation," Materials Science and Engineering: A $485.12008,367-374$.

[7] M. Grujicic, G. Arakere, B. Pandurangan, J.M. Ochterbeck, C-F. Yen, B.A. Cheeseman, A.P. Reynolds, and M.A. Sutton, "Development of a robust and cost-effective friction stir welding process for use in advanced military vehicles," Journal of Materials Engineering and Performance 20.1, 2011, 11-23.

[8] S. Mandal, J. Rice, A.A. Elmustafa "Experimental and numericalinvestigation of theplunge stage in friction stir welding" journal of materials processing technology 203 ( 20008 ) 411-419.

[9] Đurđanović, M. B., Mijajlović, M. M., Milčić, D. S., Stamenković, D. S.,. Heat generation during friction stir welding process. Tribology in Industry, 2009, 31(1-2), 8-14.

[10] Zhang, Z., Zhang, H. W.,. Numerical studies on controlling of process parameters in friction stir welding. Journal of materials processing technology, 2009,209(1), 241-270.

[11] Vinayak Malik, Sanjeev N K, H. Suresh Hebbar, Satish V. Kailas "Investigations on the Effect of Various Tool Pin Profiles in Friction Stir Welding Using Finite Element Simulations” Procedia Engineering 97 ( 2014 ) $1060-1068$.

[12] Zhao Zhang, Qi Wu, Hong-wu Zhang "Numerical studies of effect of tool sizes and pin shapes on friction stir welding of AA2024-T3 alloy" Trans. Nonferrous Met. Soc. China 24(2014) 3293-3301.

[13] Zhang, Z., Liu, Y. L., Chen, J. T.,. Effect of shoulder size on the temperature rise and the material deformation in friction stir welding. The International Journal of Advanced Manufacturing Technology, 2009,45(9-10), 889-895.

[14] M. Grujicic, G. Arakere, B. Pandurangan, J.M. Ochterbeck, C-F. Yen, B.A. Cheeseman, A.P. Reynolds, and M.A. Sutton "Computational Analysis of Material Flow During Friction Stir Welding of AA5059 Aluminum Alloys" JMEPEG (2012) 21:1824-1840.

[15] H.W. Zhang, Z. Zhang, J.T. Chen“The finite element simulation of the friction stir welding process"Materials Science and Engineering A 403 (2005) 340-348. 